\title{
Diagnosis of the problems in Korean military force development systems
}

\author{
Chunsoo Kang ${ }^{*} \cdot$ Juchan $_{\text {Kim }}^{* *}$
}

The Republic of Korea (ROK) military has pursued development with a focus on the defense force development system since the Yulgok project, which began in the 1970s for the purpose of self-defense. Currently, the ROK defense force development system seems to be very methodical, and it determines requirements by using the joint combat development system, reflects the budget in the defense planning and management system, and manages the acquisition project in the defense acquisition system; however; it has many problems.

These problems include fierce competition among the services, limited verification, ambiguous standards and references for requirements, complicated procedures and regulations, and failure to reflect the rapid changes in the security environment and science and technology in military force development. The most important issue is that the Joint Chiefs of Staff should lead the development of the forces based on the concept of joint operations; however, they are focused on only the current

(a) (1) This work is licensed under a Creative Commons Attribution 4.0 International License.

* (First Author) Kwangwoon University, Department of Defense Acquisition Program, Ph.D. Candidate, (Advisory Board for National Defense Reform, Consultant), choekang@korea.com

** (Corresponding Author) Kwangwoon University, Department of Public Administration, Professor, jckim@kw.ac.kr 
operation and neglect their main goals as the top military organization, such as mid- to long-term force development and military strategy. The Joint Chiefs of Staff should revise the organization, mission performance system, and regulations to properly perform the core functions of the defense organization that establishes long-term response strategies and builds response capabilities according to the changes in the security and strategic environment.

Keywords : force development, joint combat development system, defense planning and management system, defense acquisition system 


\section{I. 서론}

군사력 건설은 국가와 국민의 안위를 결정하는 국방의 근간을 튼튼하게 구축하는 대단히 중요한 일이며(Bae, Ku, Park, \& Kim, 2020; Lee, 2020; Lee, 2018), 대규모 예산이 투입되기 때문에 소요결 정부터 예산반영, 사업관리까지 매우 복잡한 절차를 거치도록 규정되어 있고 최종적으로 국회의 승 인까지 받게 되어 있다. 한국군은 1970년대에 자주국방의 기치를 내세우고 시작된 율곡사업을 추진 하면서부터 효율적인 군사력 건설을 위해 다각적인 연구와 여러 차례의 제도개선을 추진하여 왔다 (Seo \& Kim, 2017). 초기에는 개별 무기체계의 필요성과 가용예산을 주로 고려하다가 80년대 초부 터 국방예산을 효율적으로 사용하기 위해 미국의 국방기획관리제도를 도입하였으며, 2006년도에는 각 군에서 수행하던 무기체계 획득과 군수품을 조달하고 방위산업 육성을 관장하기 위하여 방위사 업청이 개청되었다. 그 외에도 효율적인 군사력 건설을 위해 다각적인 연구와 여러 차례의 제도개 선을 시도하였다.

그러나 지금까지의 대부분 연구나 제도 개선이 근본적인 문제의 핵심에 접근하지 못한 채 드러 난 문제를 해결하기 위하여 부분적이고 단편적으로 진행되어 온 결과, 절차가 점점 더 복잡해지고 벽이 더 생겨나는 현상이 발생하여 효율은 떨어지고, 시간은 지연되고 있다. 단편적인 예를 들면 2006년에 개청된 방위사업청의 직제규정은 15 년간 44회 개정되었다.1) 군사력 건설 시스템은 방위 사업청 외에도 각 군 본부, 합동참모본부, 국방부 등이 연계된 체계라는 것을 고려하면 한국군이 군사력 건설 시스템을 발전시키려고 많은 노력을 기울였다고 볼 수도 있지만, 근본적인 문제해결에 접근하지 못하고 단편적으로 접근하고 있다는 것을 방증한다고 볼 수 있다. 현재 한국군의 군사력 건설 시스템은 합동전투발전체계에서 소요를 결정하고 소요가 결정되면 국방기획관리체계에서 예 산을 반영하고 국방획득체계에서 획득사업을 관리하는 표면적으로는 아주 체계적이고 합리적인 제도로 보이지만 실제 현장의 상황을 세부적으로 보면 많은 문제점을 가지고 있다. 본 연구는 한국 군 군사력 건설 시스템에 내재된 문제와 시스템이 정상적으로 작동하지 않는 이유를 구체적인 사 례를 들어 분석하고 개선 방향을 제시하고자 한다.

\section{ㅍ. 한국군의 군사력 건설 시스템}

한국군 군사력 건설 시스템(Seo \& Kim, 2017)은 (1) 작전개념을 정립하고 요구되는 능력과 군사 력 건설의 콘텐츠(Contents)를 결정하는 합동전투발전체계(군사적 영역), (2) 군이 결정한 소요를 획득하기 위해 국방예산을 합리적으로 관리하는 국방기획관리체계(관료적 통제의 영역), (3) 소요 가 결정된 군수품을 개발하거나 구매하는 국방획득체계(사업관리의 영역)로 구성되어 있으며 각

1) 국가법령정보센터 홈페이지(https://www.law.go.kr/방위사업청과 그 소속기관직제, 연혁과 부칙 참고, 검색일 : 2021. 7. 14) 
체계는 상호 유기적으로 연계되어 있다(Figure 1).

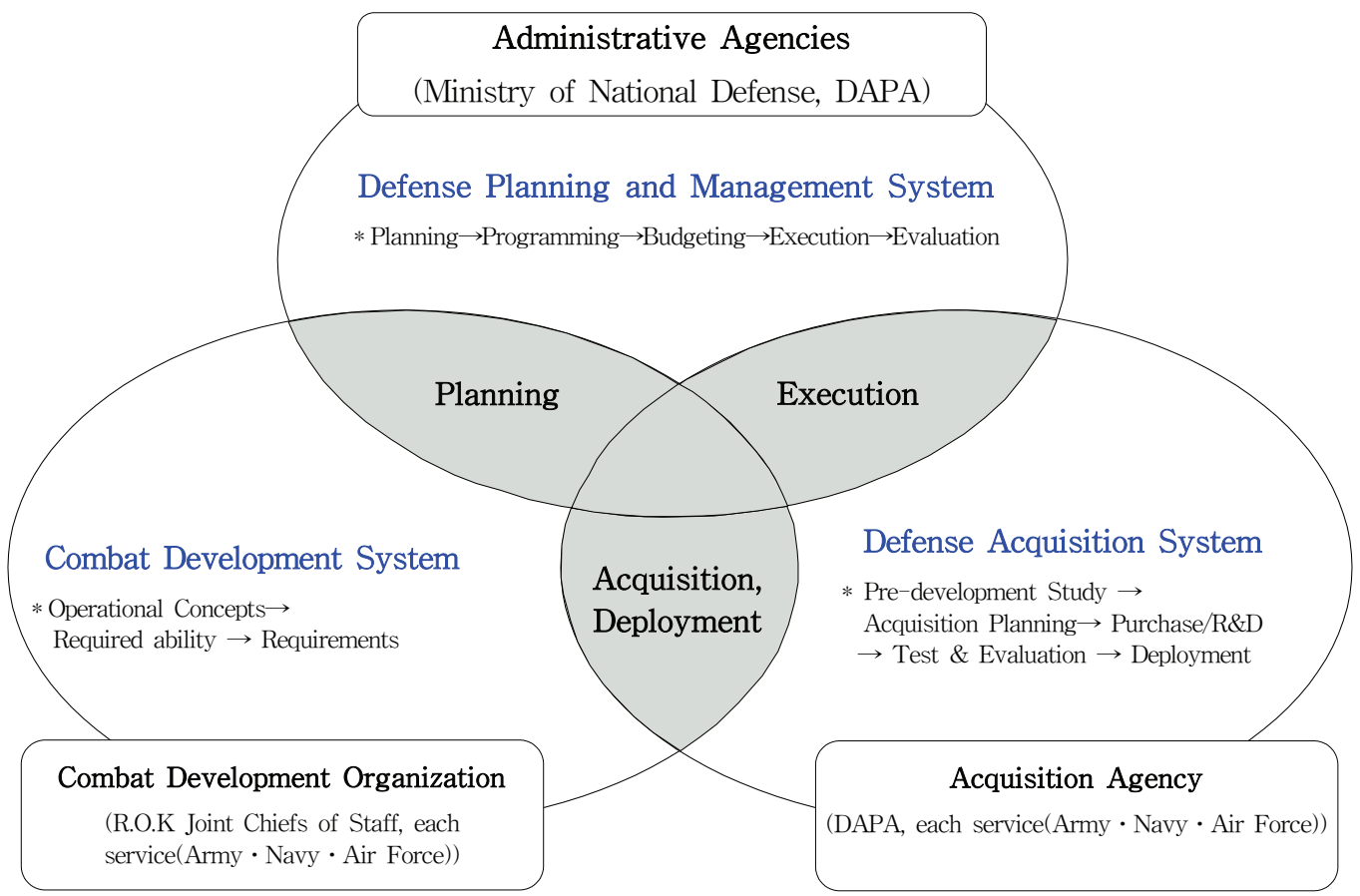

$<$ Figure 1> Force Development System of Korea (adapted from Seo, Jang, and Kim (2017)

전투발전체계를 규정한 합동전투발전훈령에 따르면 합동전투발전단계2)(절차)는 합동개념발전, 능력평가, 능력요구, 소요결정의 4단계로 구분하고 각 단계에서 필요한 경우 합동실험을 실시한다 (Figure 2).

합동개념발전 단계에서 '미래 전쟁의 모습을 구상하고 싸우는 방법'에 대한 개념을 제시하는 합 동작전기본개념서를 작성하고 미래 합동작전개념을 구현하기 위하여 싸우는 방법과 이에 필요한 능력을 구체화하여 합동작전요구능력서를 작성하고 능력평가 단계는 미래에 요구되는 능력(To $\mathrm{Be})$ 과 현재 능력(As-Is)을 비교, 분석하여 부족 능력을 식별하고 이를 극복하기 위한 최적의 대안 을 수립하여 소요제기기관(각 군이나 합동작전부대)이 갖추어야 할 군사력의 소요를 제기하도록 소요제기지침서를 하달한다. 각 군이나 합동부대 등 소요제기 기관들은 소요제기지침서에 제시된 대안에 대하여 작전요구능력 또는 발전방향을 도출하여 소요제기서를 작성하여 합참으로 제출하 게 되며 합참에서는 각 군이 제출한 소요제기서를 검토하고 소요를 구체화하여 전력소요서(무기, 장비, 물자 등)와 전투발전소요서(교리, 편성, 훈련 등 비물자적 소요)를 작성하여 전력소요는 관련

2) R.O.K. Joint Chiefs of Staff, Joint Combat Development Instruction, Article 22, page. 9-10. 
Diagnosis of the Korean military force development systems-related ... / Chunsoo Kang • Juchan Kim 5

기획문서인 합동무기체계기획서와 합동군사전략목표기획서에 반영하고 전투발전소요는 해당부서 에 반영을 요청하게 되어있다.

국방기획관리체계3)는 국방목표를 설계하고 설계된 국방목표를 달성할 수 있도록 최선의 방법을 선택하여 더욱 합리적으로 자원을 배분 - 운영함으로써 국방의 기능을 극대화하는 관리활동을 말 하며 기획, 계획, 예산편성, 집행, 분석평가 5 개의 체계가 상호 유기적으로 연관된 체계이다. 군사력 건설 시스템상에서 국방기획관리체계는 합참을 중심으로 결정된 군사력 건설 소요들을 기초로 군 사력 건설목표를 설계(기획)하고, 설계된 군사력 건설 목표를 달성할 수 있도록 최선 방법을 선택 (계획)하여 보다 합리적으로 자원을 배분 - 운영(예산 및 집행)함으로써 효율적으로 군사력을 건설 하고 제한된 예산 내에서 군사력을 극대화시키기 위한 관리 활동이라고 볼 수 있다. 기획은 합참을 중심으로 군에서 요구한 소요를 기초로, 계획과 예산편성은 방위사업청과 각 군의 협업하에 국방부 주도로 진행되며 집행은 무기체계는 방위사업청에서, 전력지원체계는 각 군(군수사)에서 집행하고 분석평가는 단계별로 각 군, 합참, 국방연구원 등 다양한 기관에서 실시하는 매우 복잡한 체계를 유지하고 있다.

소요가 결정된 군수물자를 연구개발하거나 구매하기 위해서는 앞서 설명한 국방기획관리체계상 의 기획, 계획, 예산편성 과정을 거쳐 매년 국방예산으로 편성되어 각각의 집행기관으로 배정된다. 배정된 예산을 집행하여 군수물자를 획득하는 국방획득체계는 국가안보의 실체인 군사력의 건설 과 유지를 위한 가장 중요한 체계이다. 특히, 연구개발사업은 현재 존재하지 않는 물자나 장비를 수명이 30 40년 또는 그 이상 요구되는 내구성 높은 무기체계를 개발해야 하므로, '소요결정-선 행연구-탐색개발-체계개발-시험평가-규격화/목록화'의 복잡한 절차를 거치게 되어 상대적으로 많 은 기간이 소요된다. 따라서 연구개발사업은 대부분 사업 기간이 길고 여러 기관이 기관별로 역할 이 구분되어 있으며 기관별 독립적 절차로 추진된다(Table 1).

\section{III. 한국군 군사력 건설 시스템 분석}

앞에서 살펴본 것처럼 한국군의 군사력 건설 시스템은 합동참모본부에서 소요군과 연계하여 소 요를 결정하고 소요가 결정되면 국방부에서 예산을 반영하고 방위사업청(전력지원체계는 각 군 본 부)에서 획득사업을 관리하도록 규정되어 있다. 이는 기관별 견제와 균형을 통한 투명성을 보장하 고 국방예산의 효율적인 운영을 추구하기 위하여 대부분의 민주주의 국가에서 채택하고 있는 체계 이다. 그러나, 한국군의 경우 제도도입과정에서 일부 조정과 독특한 업무추진 관행 등으로 인하여 군사력 건설 현장의 상황을 세부적으로 분석해보면 많은 문제점을 가지고 있다. 한국군 군사력 건

3) R.O.K. Ministry of National Defense, Directive on the Defense Planning and Management Framework, Article 4 (Definitions), page $97-4$ to $97-5$. 
설 시스템에 내재된 문제들과 시스템이 정상적으로 작동하지 않는 이유를 소요결정과정, 사업관리 절차, 의사결정과정을 중점적으로 분석해보면 다음과 같다.

\section{1 소요결정과정}

한국군의 군사력 건설체계는 합동전투발전체계, 국방기획관리체계, 국방획득체계 등 3 개의 체계 로 구성되며, 각각의 체계는 주관부서가 다르고 독립된 절차에 따라 업무가 수행된다. 3 개의 독립 된 체계의 공통부분이 소요이며, 소요는 군사력 건설의 시작이며 소요를 충족시키는 것이 군사력 건설 시스템의 산물이기 때문에 군사력 건설에 있어서 가장 중요한 부분이라고 볼 수 있다.

따라서 대부분 국가에서 군사력 건설의 소요를 합리적으로 결정하기 위한 정책적인 노력을 기울 이고 있으며 한국군도 군사력 건설 시스템과 연계하여 전력 소요기획에 관하여 다년간의 연구와 제도적 보완을 거쳐 2014년부터 합동전투발전체계를 규정화하였다. 합동전투발전훈령에 따르면 합 참에서 국방정보판단서와 합동군사전략서(JMS)4)에 근거하여 합동작전개념을 발전시켜 미래합동 작전개념서를 작성하고, 합동작전개념 수행에 필요한 합동작전요구능력서를 작성하여 각 군에 하 달하고 요구능력과 현재의 능력을 평가하여 소요제기지침서를 작성하여 각 군과 작전부대에 하달 하게 되면, 각 군이나 작전부대에서는 요구능력서와 소요제기지침서를 기준으로 요구능력을 구체 화하여 전력소요제기서를 작성하게 된다. 합참에서 전력소요를 종합하고 검토하여 소요를 결정하 여 합동군사전략목표기획서(JSOP)5)에 반영하면 문서 간의 연계성이나 합동성은 자동으로 고려되 어 반영되도록 규정되어 있다. 그러나 우리 군은 절차는 잘 만들었으나 조직별 기능을 부여하고 편 성을 조정하고 세부절차를 구체화하는 등의 후속 조치가 미흡하여 실제 전력소요 결정과정을 보면 훈령에 제시된 것처럼 논리적인 절차로 진행되지 못하고 있다.

\section{1 .1 각 군 간 경쟁과 중복투자 검증 제한}

합동전투발전체계와 국방기획관리체계의 실질적인 업무수행의 흐름은 Figure 2에서 보는 바와 같다. 합동전투발전체계의 책임 부서는 합참의 전투발전부이며 합참에서 합동작전기본개념서를 작 성하고 이에 기초하여 요구능력서와 소요제기지침서는 하달되고 있지만, 미래합동작전기본개념서 나 요구능력서가 국방기획관리 규정상의 문서로 정해지지도 않았고 작성간 각 군의 의견을 반영하 는 절차도 무기체계 소요결정 과정(합동전략실무회의-합동전략회의-합동참모회의)에 검토의 기준

4) 합동군사전략서(JMS: Joint Military Strategy)는 향후 15년간의 장기 군사전략 목표, 군사전략 개념 및 군사력 건설 방향을 제시하는 문서로 5 년 주기로 합참(전략기획부)에서 작성하고 국방부 장관의 승인을 받는다.

5) 합동군사전략목표기획서(JSOP: Joint (Military) Strategic Objectives Plan, 合同軍事戰略目標企劃書)는 국방목표 달성을 위한 군사전략과 합동전장운용개념에 의한 중장기(F+3년 $\sim \mathrm{F}+7$ 년 $)$ 군사력 건설 방향, 무기체계 기획 및 부대 기획이 수록된 기획문서로 국방 연구개발 정책 및 국방중기계획 수립을 위한 기초 자료를 제공한다. 합동참모본부 전력기획부에 서 국방정보판단서, 국방기본정책서, 합동군사전략서 및 합동전장운용개념 등을 기초로 매년 작성한다. 
에도 포함되지 않는다.

합동전투발전체계와 전력기획체계가 유기적으로 연계되어야 하지만 현실에서는 각 군은 자군의 영역을 확장하기 위하여, 각 군 본부 참모부는 해당 부서의 업무추진실적을 제시하기 위하여 합참 (전투발전부)에서 하달한 요구능력서나 소요제기지침서를 초과하는 많은 소요를 제기하게 된다. 소요결정 과정에서 각 군에서 제기한 소요에 대하여 합동성, 중복투자에 대한 검증, 요구능력서나 소요제기지침서를 초과하는 소요인가에 대한 검증이 제대로 이루어지지 못하는 구조이다. 그러다 보니 합참이 군사전략과 합동전장운용개념에 기초하여 군사력 건설을 주도하는 것이 아니라 각 군 이 주도(요구)하는 군사력 건설을 합참에서 조정하여 기획문서에 반영해나가는 현실이다.

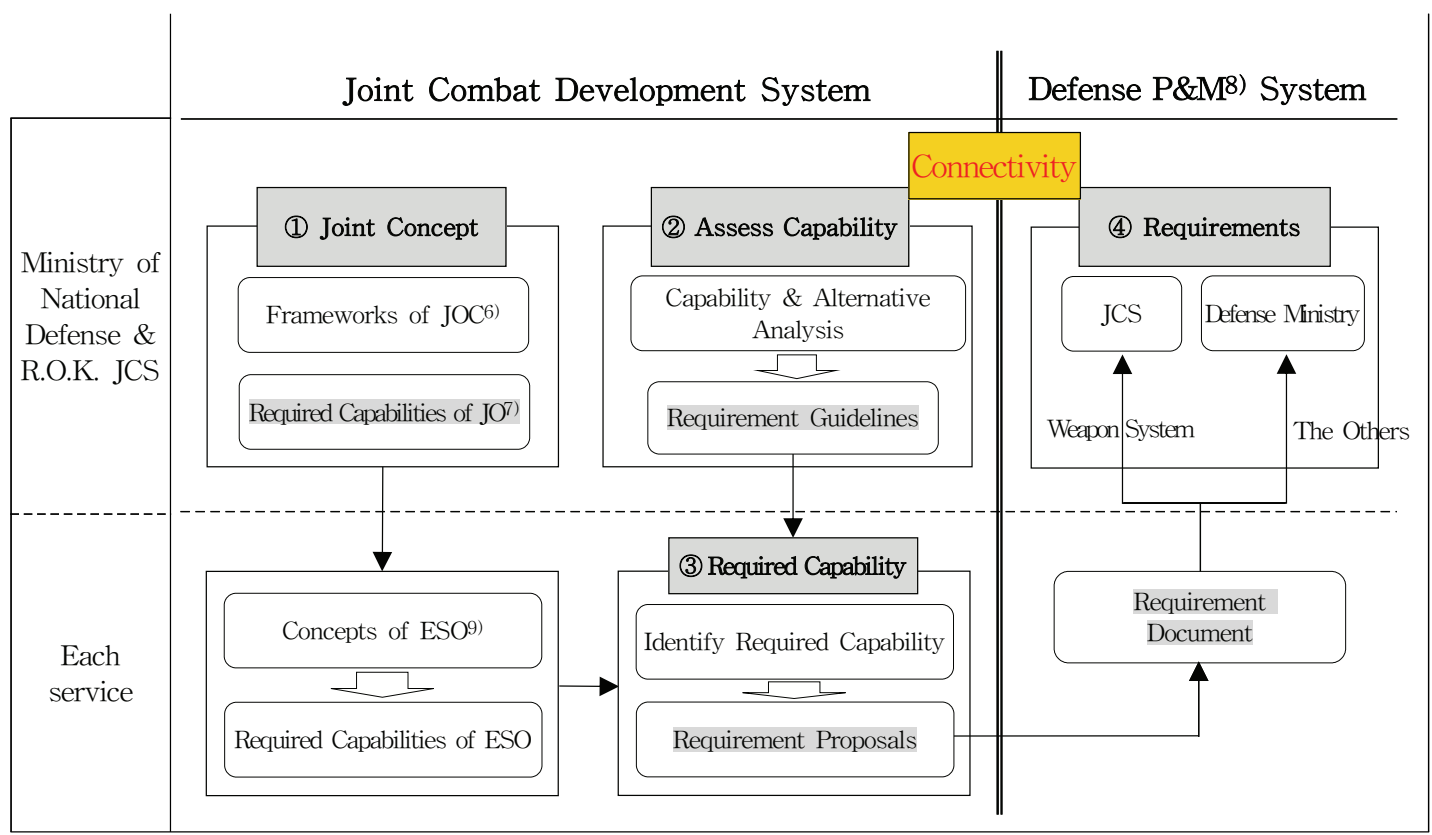

<Figure 2> Procedure of Joint Combat Development System: Defense Planning and Management System

Source: Joint Combat Development System from attached Table 2 in Joint Combat Development Instruction

합참에서 명목적으로는 소요를 결정하지만, 전력소요를 결정하는 과정에서 합동전장운용개념에 기반을 두고 주도하기보다는 각 군에서 제기된 전력을 심의하여 결정하다 보니 각 군의 영향력에 의해 결정되거나 여론에 편승하여 결정되는 경우가 많다. 전력소요를 결정하는 합참의 의사결정권

6) JOC: Joint Operation Concept.

7) JO: Joint Operation.

8) P\&M: Planning and Management.

9) ESO: Each Service Operation. 
자들은 각 군의 인사권에서 벗어날 수 없으므로 각 군은 자군의 영역을 확장하기 위한 무한경쟁을 펼치고 있는 현실이다.

대표적인 사례들이 과거 북한의 장사정포 위협 대응, 연평도 포격전 이후 대비태세 보완, 북한의 핵 $\mathrm{WMD}$ 대응 등의 과정에서 합참이 주도적, 선제적으로 역할을 수행하지 못하여 각 군간 치열하 게 주도권 경쟁을 하면서 외부의 힘까지 의존하는 경우도 발생하였고 미래전의 핵심전력으로 중요 성이 부각되고 있는 드론, 우주전력에 관해서도 각 군의 주도권 다툼의 장으로 변질되고 있다. 합참 에서 전략적, 작전적 필요 때문에 군사력 건설 소요가 결정되었다면 보라매 사업, 경항모 사업 등 대형사업의 필요성을 합참(작전이나 전투발전)에서 주도하여 필요성을 설명하면 되는 것을 군정부 대인 각 군이 주도하여 국회, 언론 등을 설득하고 민간 연구기관에서 용역연구를 통해 결론을 도출 하는 이상한 현상이 계속되고 있다.

그나마 무기체계의 경우는 합참 전력기획참모부에서 개별 무기체계 소요의 타당성이나 중복 문 제를 검토하는 정도라도 각 군에서 제기된 소요를 검토하여 기획문서에 반영한 데 비해 무기체계 외의 장비나 물자는 국방부의 해당 부서에서 검토가 종결되는 구조로 전투발전조직이 아닌 국방부 에서 합동성 차원에서의 검증할 수 없다(Seo, Jang, \& Kim, 2017).

\section{1 .2 미래 안보환경 변화에 대비 역량 부족}

국방전력발전업무훈령에 따르면 신규 전력소요는 우선 장기 전력소요로 결정하여 소요를 반영 한 후 정해진 절차를 거쳐 중기 전력소요로 반영함을 원칙으로 한다. 다만, 사변 - 해외파병 - 적의 침투 - 도발 또는 테러 등과 관련하여 긴급하게 무기체계 등의 소요가 필요한 경우에는 중기신규 또는 긴급 전력소요로 결정할 수 있으며, 이때 긴급 전력소요는 중 - 장기전력 소요결정 절차를 준 용한다.10) 즉, 군사력 건설의 소요결정 과정은 장기소요로 우선 결정하고 중기소요로 결정하는 과 정에서 사업타당성 조사와 선행연구 등 사업추진에 필요한 검토와 준비에 필요한 충분한 시간을 갖고 소요군의 요구사항도 구체화되어야 한다. 소요결정 과정과 내용은 모두 군사기밀로 분류되어 자료수집이나 공개할 수 없지만, 연간 합참에서 결정하는 전력소요의 약 절반 정도는 긴급전력이나 중기 신규전력으로 장기 소요결정 단계를 거치지 않고 결정되고 있다.

특히 2015년과 2016년과 같이 북핵 위협이 현실화되면서 이에 대한 대응으로 3축 체계에 대한 전력소요가 대부분의 중기신규 및 긴급전력으로 편성되었다. 이는 북한의 핵무장에 대하여 2015년 전까지는 대응개념이나 군사력 건설 소요를 도출하지 않고 2015년부터 북한의 핵실험이 공개되면 서 급하게 대응개념을 설정하고 전력소요를 제기하다 보니 대부분 중기신규전력이나 긴급전력으 로 소요를 결정하거나 장기 신규전력으로 소요를 결정하고 급하게 다시 중기소요로 전환하는 상황 이 발생하였음을 의미한다. 그 당시 상황이 얼마나 다급했으면 군에서 '우리가 독자적 정찰위성 능

10) ROK Ministry of National Defense, Defense Force Development Instruction Article 29 (Procedures for Requesting and Determining Requirements) Paragraph (3) 
Diagnosis of the Korean military force development systems-related ... / Chunsoo Kang • Juchan Kim 9

력을 확보하려면 2023년은 가야 한다. 그때까지의 공백을 메우기 위해 위성을 임차하는 방안도 협 의할 예정'11)이라는 보도가 2016년 10월 18 19일 주요뉴스로 전 매체에 공개되었다. 위성을 임대 한다는 계획은 1년이 채 안 되어 사라지고 다음 해인 2017년 국정감사에서 질타를 받는다. 2017년 10 월 13일 방위사업청 국정감사12)에서 “지난 4월 24일 방사청은 독일, 프랑스, 이스라엘 등 4개국 이 모두 (임차를) 거부했다”라며 “(임차가 어렵다는 것을) 뻔히 아는데 $\mathrm{O}$ 교수에게 작업13)을 요청 했다.”라고 지적했다. 다급하고 무책임한 임기응변식 소요제기와 결정으로 많은 시간과 비용을 낭 비했지만 질타나 비난으로 종결되었다.

\subsection{3 소요에 대한 근거나 기준 모호}

Seo, Jang, and Kim (2017)은 “기획관리 조직이 소요를 결정함으로써 국회, 기획재정부 등 외부 에서 소요검증 요구 시 전투발전 소요창출 논리를 적시에 제공하기 곤란하다”라고 주장한 대로 외 부에 대응도 문제지만, 군사력 건설 소요와 사업의 연계성 측면에서 소요에 대한 구체적인 근거나 기준이 모호하다는 문제점이 제기된다. 대표적인 사례로 차기 전술교량사업은 2003년 소요가 결정 된 사업으로 교량 길이를 당시 세계에서 가장 긴 $60 \mathrm{~m}$ 로 설정했다. 선행연구 결과를 바탕으로 2007 년 국내기업이 연구개발하여 2011년부터 2013년 6월까지 진행된 6차례 시험평가에서 요구성능에 미치지 못하여 2014년 2월 최종적으로 사업실패로 종결되었다. 개발했던 교량은 당시 세계 최고 수 준 $(55 \mathrm{~m})$ 에 근접한 $53 \mathrm{~m}$ 급 교량인 데 비해 군이 요구한 성능 목표치인 $60 \mathrm{~m}$ 에 미달했다는 이유로 사 업은 실패로 귀결됐다(Kim, 2018). 2014년 사업실패로 결정된 후 2015년 군은 요구성능을 낮추어 다시 소요를 제기하고, 선행연구결과 2019년에 사업을 Block- I (44m), Block- II (52m)로 단계화하 여 추진하는 방법으로 사업을 다시 추진하는 것으로 결정하였다.14) 전술교량이 필요하고 필요한 교량의 길이가 $60 \mathrm{~m}$ 라는 것이 전투수행개념을 기초로 산출되고 불요불급한 소요였다면, 2003년도 에 요구한 전술교량이 아직 전력화되지 않고 20년 가까이 지나서 훨씬 낮은 성능으로 단계화하여 다시 소요를 결정하겠는가? 소요결정 시 합동전투발전체계에 명시된 합동작전수행개념에 기초하 거나 전투실험을 거치지 않았고 소요검증, 선행연구 등의 단계에서도 국내외 기술수준에 대한 정보 수집과 분석, 개발 가능성에 판단도 제대로 이루어지지 않았기 때문에 이런 상황이 발생하였고 현

11) 이정진(2016.10.18). 軍, ‘北동향 감시’ 정찰위성 임대추진...이스라엘 거론. 연합뉴스. https://www.yna.co.kr/view/ AKR20161018120500014

12) 홍기삼, 조규희, 문대현 (2017.10.13.). 위성 임대 무산 - 주요사업 지연 ‘질타'‥방사청 국감(종합), 뉴스1. https://www. news1.kr/articles/?3123310

13) 당시 김중로 의원의 주장은 방위사업청이 이미 각국으로부터 임차가 불가하다는 통보를 받고도 용역 연구를 추진하고 있다는 지적이었으며 용역을 담당한 항공대 O교수는 국정감사에 증인으로 출석하여 "타국이 운용 중인 군 정찰 위성을 임차한다는 생각이 가능한 개념은 아니다.”라고 증언하였음(뉴스1, 2017. 10.13).

14) 양낙규 (2020.11.23). 차기 전술교량사업 17년 만에 재추진. 아시아경제. https://www.asiae.co.kr/article/2020112309 100561046 
재의 소요결정 절차는 앞으로도 동일한 사례가 계속 발생할 가능성을 내포하고 있다.

\subsection{4 군사력 건설 소요와 사업의 연계 문제}

전투발전조직이 아닌 기획부서에서 소요를 결정하면서 발생하는 현실적인 문제는 군사력 건설 소요를 획득사업으로 연결하는 문서인 운용요구서(ORD: Operational Requirements Document)가 소요결정과정에서 작성되지 않는다는 점이다. 운용요구서는 소요 무기체계의 임무요구 충족에 필 요한 세부적인 운용능력을 기술한 문서로써 군 요구도 설정 및 시험평가기준으로 활용되는 무기체 계 획득 사업관리상의 핵심문서이다. 순리적으로 보면 소요제기 과정에서 운용능력이 제시되고 제 시된 내용을 소요제기기관에서 작성하는 것이 타당하나 우리 군은 작성을 꺼리고 있어 현재는 사 업을 관리하는 방위사업청에서 주로 용역으로 운용요구서를 작성하는 현실이다.

소요를 제기하면서 합동작전개념이나 전투실험 자료 등을 근거로 하지 않고 기획부서의 실무자 선에서 소요문서를 작성하게 되어 소요문서는 주요 성능과 소요량, 전력화 시기 위주로 작성하여 사업관리자에게 넘긴다. 사업관리자가 민간용역을 통해 작성한 운용요구서는 사업관리 과정이나 시험평가 단계에서 소요기관과 이견이 발생할 수밖에 없고 발생한 문제에 대하여는 소요문서에 명 시되지 않아 쉽게 동의하지 않아 사업을 지연시키는 사례가 다수 발생하게 된다. 방위사업청에서는 소요제기 기관에서 운용요구서를 작성할 것을 수차 요구하였으나 합참과 각 군에서는 이를 기피하 여 시정되지 않고 있다.

\section{2 절차의 복잡성과 경직성}

우리 군의 군사력 건설체계는 비리를 예방하기 위하여 견제와 균형에 집중하여 기관별 별도의 법규에 따라 진행되다 보니 절차가 경직되어 있다. 사업 진행 간 문제가 발생하면 기관 간 협조나 조정이 매우 어렵고 문제해결에 필요한 조치를 어느 기관에서 담당할 것인지를 결정하기가 어렵고 서로 다른 기관에 선행조치를 요구하게 된다. 적극적으로 문제를 해결하기보다는 속된 표현으로 면 피성 또는 폭탄 돌리기 같은 업무행태가 발생하기 쉽다.

Table 1에서 제시하고 있는 각각의 단계에서 책임기관은 앞 단계에서 산출된 결과를 받고 나서 해당 기관에 부여된 단계를 진행하고 중간에 문제가 생기면 다시 소요단계로 돌아가 처음부터 다 시 순서대로 진행하는 경직된 업무수행방식을 따르고 있다. 이런 업무수행은 업무 관련 이해 당사 자 간의 견제와 균형이나 사업관리의 투명성 측면에서 긍정적 효과를 기대하고 만들었다고 할 수 있다. 그러나 기관 간 협업이 어려워지고 선행연구, 소요검증, 사업타당성 조사 등 사업관리의 핵심 국면에서 이루어지는 중요한 결심을 담당해야 할 정부 공무원들이 행정적 책임이 없는 산하 출연 기관이나 민간 연구소의 연구결과에 의존함에 따라 사업관리의 책임성이 약화되고, 조직의 효율성 이 저하될 가능성이 상존한다. 
$<$ Table 1> Acquisition Procedures and Responsible Agencies for Weapon System

\begin{tabular}{l|l}
\hline \multicolumn{1}{c|}{ Phases } & \multicolumn{1}{c}{ Agencies } \\
\hline \hline (1) Requirement Proposal & HQs of Each Service \\
\hline (2) Requirement Decision (Long-Term) & Joint Chiefs of Staff \\
\hline (3) Preliminary Research & DAPA15) (DTAQ16)) \\
\hline (4) Requirement Decision(Mid-Term) & Joint Chiefs of Staff \\
\hline (5) Acquisition Strategy & DAPA \\
\hline (6) Requirement Verification & MND17) (KIDA18) \\
\hline (7) Program Feasibility Study (R\&D) & MSAF19) (KIDA) \\
\hline (8) Budgeting & MND, MSAF \\
\hline (9) Execute Program (R\&D, Purchase) & DAPA (ADD, Company) \\
\hline (10) Test \& Evaluation & Joint Chiefs of Staff \\
\hline (11) Program Feasibility Study (Mass Production) & Ministry of Strategy and Finance (KIDA) \\
\hline (12) Budgeting & MND, MSAF \\
\hline (13) Deployment & DAPA (Each Service) \\
\hline
\end{tabular}

복잡하고 경직된 업무수행절차에 의해 발생되는 문제점의 사례는 다수가 있으며 그중 하나가 $\mathrm{CH} / \mathrm{HH}-47$ 성능개량사업이다. $\mathrm{CH} / \mathrm{HH}^{-47}$ 성능개량사업 추진경과를 연도별-기관별로 도식하면 Table 2 와 같다. 다른 사업과 동일하게 최초소요는 각 군의 소요제기를 검토하여 합참에서 결정하 고 필요에 따라 수정하게 되었고 선행연구는 방위사업청에서 국방기술품질원의 기술수준 조사분 석 지원을 받아 시행하며 사업타당성 조사20)는 기획재정부에서 예산반영을 위해 요구하는 사항으 로 기획재정부에서 지정한 한국국방연구원에서 수행하였다.

최초 소요결정은 사용 중인 헬기의 수명이 도래함에 따라 각 군에서 제기하고 합참에서 성능개 량이 필요하다고 판단하여 소요를 결정하면서 성능개량을 했을 때 요구성능과 성능개량 시기(2018 2026)21)를 결정하게 된다. 최초 결정된 소요량(A)을 대상으로 한 선행연구 결과는 국외구매로 결정 되었으나, 14 대를 추가 도입함에 따라 소요량을 수정하고 다시 실시한 2 차 선행연구결과는 국내연

15) DAPA: Defense Acquisition Program Administration (방위사업청)

16) DTAQ: Defense Agency for Technology and Quality (국방기술품질원)

17) MND: Ministry of National Defense (국방부)

18) KIDA: Korea Institute for Defense Analyses (한국국방연구원)

19) MSAF: Ministry of Strategy and Finance (기획재정부)

20) 사업타당성 조사는 타 부처 사업의 예비타당성조사와 유사한 개념으로 방위사업법이나 국방획득관리훈령에 따른 절차는 아니며 기획재정부에서 예산편성을 위해 시행하는 절차이다. 예비타당성조사는 국가재정법 제 38 조 및 동법 시행령 제 13 조의 규정에 따라 대규모 신규 사업에 대한 예산편성 및 기금운용 계획을 수립하기 위하여 기획재정부장관 주관으로 시행하는 사전적인 타당성 검증 - 평가를 말한다.

21) 방위사업청 보도자료(20. 12. 15). 제132회 방위사업추진위원회 결과. 
구개발로 결정되어 사업예산 반영을 위해 사업타당성 조사를 실시한 결과 추가로 도입한 14 대는 성능개량이 제한되어 제외해야 한다고 판단하였다. 이에 따라 합참에서 다시 소요를 수정하여 최초 결정했던 소요량 $(\mathrm{A})$ 으로 다시 선행연구를 실시하고 사업타당성 조사결과, 생산업체에서 단종된 $\mathrm{CH} / \mathrm{HH}-47 \mathrm{D}$ 모델을 성능개량 하는 것보다 현재 미군이 사용하고 있는 $\mathrm{CH} / \mathrm{HH}-47 \mathrm{~F}$ 모델의 동체 를 사용하며, 기존 헬기를 분해 수리한 후 사용 가능한 부품들을 골라내어 새 동체에 결합하는 리뉴(Re-New) 방식의 성능개량안(案)을 권고하고 일부(B)는 새 헬기를 구매하는 방안을 권유하였 다. 최종적으로 수정된 성능개량 소요(A-B)를 대상으로 한 선행연구 결과 일정, 성능, 비용 등을 종합적으로 고려하여 제 132 회 방위사업추진위원회에서 $\mathrm{CH} / \mathrm{HH}-47 \mathrm{D}$ 성능개량사업을 중단하는 것 으로 심의 - 의결하였다. 결과적으로 이 사업은 소요가 결정된 후 14 년간 사업에 착수하지도 못하 고 소요결정에서 사업개시 전에 필요한 소요검증-선행연구-사업타당성 조사 절차만 2 3회 반복 하면서 시간과 노력을 낭비하고 중단되었다.

$<$ Table 2> $\mathrm{CH} / \mathrm{HH}-47$ Improvement Project Progress22)

\begin{tabular}{l|l|l|l}
\hline Year & Decide/Revise Requirement & Preliminary Research (Result) & Feasibility Study (Result) \\
\hline \hline 2007 & (1) Decide Requirement $\left(\mathrm{A}^{*}\right)$ & & \\
\hline 2012 & & (2) $1^{\text {st }}$ (Foreign Purchase) & \\
\hline 2014 & (3) Revise Requirement (A+14) & & \\
\hline 2015 & & (4) $2^{\text {nd }}$ (Domestic R\&D) & \\
\hline 2016 & & & (5) $1^{\text {st }}$ (Exclude added 14 units) \\
\hline 2017 & (6) Revise Requirement (A) & & \\
\hline 2018 & & (7) $3^{\text {rd }}$ (Domestic R\&D) & $\begin{array}{l}\text { (8) } 2^{\text {nd }} \text { (Change the process for } \\
\text { weapon system acquisition }\end{array}$ \\
\hline 2019 & (9) Revise Requirement $\left(\mathrm{A}-\mathrm{B}^{* *}\right)$ & & \\
\hline 2020 & & (10) $4^{\text {th }}$ (Terminate Project) & \\
\hline
\end{tabular}

* A: For initial decision of requirements of the Army and Air Force, the total number of current units deployed in the them.

** B: The number of new helicopters purchase, rather than performing improvement of them from firstly required number of $\mathrm{CH} / \mathrm{HH}-47$.

*** Change the process for weapons system acquisition (Research and Development or Purchase): Based on the results of the $2^{\text {nd }}$ feasibility study of weapon acquisition, it is recommended a renewal approach to performance improvement that some units (B) will be purchased in new models and others will be improved that they are replaced the old fuselage with the new $\mathrm{CH}-47 \mathrm{~F}$ fuselage and then repaired the available parts and combined them with the new after breaking down the existing helicopter.

추가도입 없이 바로 사업타당성 조사를 실시하거나 2014년에 사업타당성 조사가 실시되어 정상적 으로 추진하였다면 2015년에 사업이 착수되어 2018년부터 배치가 가능했을 것이다. 추가도입으로

22) 김대영의 무기 인사이드, 軍, 치누크 헬기 성능개량사업 17대로 확정(Nownews 2020. 1. 23) 등 인터넷 검색자료 연구자 재정리 
인해 소요량이 변했거나, 사업타당성 조사 결과를 수용한 소요 수정에도 다시 합동참모회의 의결을 거치기 위해 최소 몇 개월을 지체하고 인력과 시간을 낭비하고 있다. 사업타당성 조사 결과를 근거 로 바로 소요를 수정하면 끝나는데 소요를 수정하기 위해서는 각 군 본부 정책회의를 거쳐 합참에서 합동전략실무회의와 합동전략회의를 거쳐 합동참모회의의 의결을 거쳐 확정하기 위해 매번 약 1 년 씩을 보내게 된다. 현재 우리 군이 운용 중인 $\mathrm{CH}-47$ 헬기는 생산된 지 최소 21 년에서 최대 50년이 넘어 노후화가 심각한 상황이다.23) 수리 부속마저 단종돼 가동률이 매우 저조한 실정이다. $\mathrm{CH} / \mathrm{HH}-47 \mathrm{D}$ 헬기를 운용하는 전 세계 18 개국 중, 성능개량이나 신규 도입 없이 운용하는 국가는 우리나라뿐이다. 미군의 경우 모두 성능개량을 통하여 신형으로 개조되어 우리와 같은 기종은 부품 조달도 더는 되지 않는다. 최초 계획대로라면 2018년부터 성능 개량된 헬기가 배치되고 있어야 하는 데 지금부터 헬기를 일부 수량은 구매절차를 시작하고 나머지 대수에 대하여는 어떻게 할 것인지 대안을 마련하여야 한다. 상시 전투준비태세와 'Fight Tonight'을 외치는 우리 군에서 언제까지일지 도 모르게 몇 년간 수송 헬기 가동률이 $50 \%$ 이하로 유지될 수밖에 없는 상황이 발생하였다.

선행연구 책임기관인 방위사업청과 사업타당성 조사를 담당했던 한국국방연구원의 업무수행을 살펴보면 방위사업청은 선행연구를 4회 실시했고 한국국방연구원은 사업타당성 조사를 2 회 실시 하였다. 선행연구는 방위사업청(사업관리팀)이 국방기술품질원의 지원을 받아 해당 무기체계에 대 한 연구개발의 가능성, 소요 시기 및 소요량, 국방과학기술 수준, 비용 대 효과 등에 대한 조사분석 등을 통해 효율적인 사업추진방법 결정을 지원하기 위하여 실시하는 절차이다. 사업타당성 조사는 기획재정부의 국방사업 총사업비 관리지침에 의하여 한국국방연구원에서 총괄하며 소요분석, 사업 계획 분석, 예산의 적절성 분석, 총 수명주기 비용 분석 등을 종합적으로 고려하여 해당 사업이 재 정사업으로 추진하기에 적합한지를 검토하게 된다. 상기한 두 가지 조사의 성격이 다른 것처럼 보 이지만 해당 조사 모두 사업추진방법과 이에 따른 비용과 전력화 시기 등을 판단하는 조사로 많은 부분이 중첩됨에도 불구하고 2차 선행연구결과(4) 이후의 사업타당성 조사((5))에서는 추가로 도 입된 미군이 사용하던 헬기 14 대는 성능개량이 제한되어 제외해야 한다고 판단하게 되고 소요를 조정 $(\mathrm{A})$ 하여 다시 수행한 선행연구결과(7)를 가지고 사업타당성 조사(8)를 실시한 결과 일부(B) 는 새 헬기를 구매하고 수정된 성능개량 소요 $(\mathrm{A}-\mathrm{B})$ 로 다시 소요를 수정하게 된다. 심지어 $\mathrm{CH} / \mathrm{HH}-47 \mathrm{D}$ 기종이 단종된다는 사실도 판단하지 못하고 선행연구를 실시하고 사업타당성 조사에 서 $\mathrm{CH} / \mathrm{HH}-47 \mathrm{D}$ 의 단종에 따라 $\mathrm{CH} / \mathrm{HH}-47 \mathrm{~F}$ 형으로 성능개량으로 권유받고 성능개량 소요 $(\mathrm{A}-\mathrm{B})$ 를 대상으로 선행연구(10)를 실시한 결과 일정, 성능, 비용 등을 종합적으로 고려하여 $\mathrm{CH} / \mathrm{HH}-47 \mathrm{D}$ 성 능개량사업을 중단하는 것으로 결정하였다.

한국국방연구원에서 실시한 2 회의 사업타당성 조사는 방위사업청의 선행연구의 부족했던 점을 식별해낸 점은 인정되지만 역시 아쉬운 점이 있다. 한국국방연구원에서는 사업타당성 조사 이전에

23) 김관용 (2020.10.20.). [2020국감] 50년된 시누크 헬기, 결국 성능개량 않기로. 이데일리. https://www.edaily.co.kr/ news/read?newsId $=03247206625934888 \&$ mediaCodeNo $=257$ 
(그림에서는 도식하지 않은 부분임) 합참에서 소요를 결정하거나 수정하게 되면 소요검증 과정을 거친다. 소요검증 과정에서도 사업타당성 조사에서 식별한 문제들을 찾아낼 기회가 있었고, 1 차 사 업타당성 조사(5))에서는 단순히 미군이 사용하던 헬기 14 대는 제외해야 한다고 판단하여 소요를 조정 $(\mathrm{A})$ 하여 실시한 2 차 사업타당성 조사(8) 결과는 사업방식을 변경하도록 권고하였다. 2 년 사 이에 같은 기관에서 같은 업무를 수행한 결과는 너무도 상이하다. 물론 그사이에 $\mathrm{CH} / \mathrm{HH}-47 \mathrm{D}$ 단 종이라는 변화가 있기는 하지만 미군이 단종을 결정하고 통보했는지는 불분명하지만, 방위사업청 (국방기술품질원)과 한국국방연구원, 한국국방연구원 내의 소요검증부서와 사업타당성 조사 업무 부서 간 정보가 충분히 공유하지 못한 결과라고 본다.

Table 2와 같이 소요결정 또는 수정, 선행연구, 사업타당성 조사 등 매 단계를 거치는데 대략 1년 이 소요된다. 합참에서 소요를 결정할 때는 이런 절차들이 아무런 문제 없이 진행될 것을 가정하여 전력화 시기를 판단하는데 단계별로 1 년씩 지연되어도 개선하려는 노력은 없고 서로 다른 기관에 서 별도의 법규에 의거 시행하다 보니 자기에게 부여된 역할만 충실히 하면 된다는 업무수행관행 이 뿌리를 내렸다. 방위사업청은 국방부의 통제를 받는 정부조직이고 국방연구원은 국방부 산하 연 구기관임에도 노력을 통합하지 못하는 현상이 발생했고 우리 군의 군사력 건설 시스템의 복잡성과 경직성을 정확하게 드러낸 사례라고 볼 수 있다.

\section{3 의사결정 회피 및 지연}

무기체계획득은 앞서 설명한 것처럼 대단히 복잡하고 여러 기관이 관여하도록 규정되어 있고 단 계별로 상이한 조직에서 수행하는 분절된 체계이다. 각각의 단계가 적게는 수개월에서 길게는 1 년 이상이 소요되며 사업추진 예산에 반영하기 위한 순기24)를 경과한 경우 다음 해 예산에 반영할 수 있기 때문에 1 년이 추가로 필요하게 된다. 따라서 소요결정으로부터 사업개시까지 통상 5년 이상이 소요되는데 예기치 못한 문제가 발생하면 앞서 예를 들은 $\mathrm{CH} / \mathrm{HH}-47$ 성능개량사업처럼 계속 지연 될 가능성이 내재되어 있다. 무기체계 획득 사업관리 과정에서 문제가 발생하지 않고 절차대로 원 만하게 사업이 진행된다면 관련 기관들은 순서대로 각 기관에 해당하는 업무만 처리하면 된다. 그 러나 존재하지 않는 무기체계의 운용개념을 정립하여 요구성능을 결정하고 소요되는 비용과 시간 을 판단하여 연구개발사업을 추진하는 과정에서 예상하지 못했던 많은 문제가 발생하고 여러 가지 의사결정이 필요하게 된다. 일단 문제가 발생하면 발생한 문제에 대하여 관련 기관들이 의견을 모 아 적시적인 의사결정을 하여 사업계획에 반영하고 필요시 사업계획을 조정하도록 조치하여야 한 다. 의사결정과정에서 누가 주도하고 어떻게 해결해야 하는가의 문제가 발생한다.

이러한 문제를 극복하기 위하여 소요결정 과정에서는 합참에서 통합개념팀(ICT: Integrated

24) 예산은 국회의 심의를 거쳐 확정되기 때문에 예산에 반영하기 위해서는 회계연도 전년 9월 정기국회 개시 전에 정부안을 국회로 보내게 되고, 이를 위해서 국방부 요구안은 6 월 말까지 확정하여 기획재정부에 요구하여야 한다. 
Concept Team)을 구성하고, 사업관리 단계에서는 방위사업청 사업관리팀을 중심으로 통합사업관 리팀(IPT: Integrated Project Team)을 구성하도록 법규에 명시되어 있다. 통합개념팀(ICT)은 합동 개념 구현과 과학적 - 계량적 분석에 의한 소요창출을 위해 군사전략, 작전운용, 군 구조, 교리, 무 기체계, 과학기술 분야, 시험평가 분야 등 관련 인원으로 구성 - 운영할 수 있고 필요시 국방부 - 합 참 - 소요군의 소요기획 및 시험평가 관련 업무 담당자와 방사청 - 국과연 · 방산기술센터(필요 시) • 기품원 - 소요군의 기술전문가 및 종합군수지원 담당자, 사업관리담당자 등을 포함하여 구성할 수 있다.25) 통합사업관리팀(IPT)도 소요결정 이후 선행연구단계에서부터 사업종결 시까지의 사업관 리단계에서 중기계획 및 예산 요구, 사업내용과 예산사용계획을 구체화하고 사업추진과 관련된 제 반 업무를 관리하는 조직으로 관련 기관의 담당자들을 포함하여 편성할 수 있도록 운영되어야 한 다. 규정은 되어 있지만, 통합개념팀이나 통합사업관리팀에 편성된 외부 구성원들은 부가적인 업무 로 회의에 참석하여 간단한 의견을 제시하는 정도인데 이들에게 분명하게 임무를 부여하고 해당 기관의 의견을 심도있게 검토하여 반영하도록 규정을 개정하여야 한다.

시험평가 과정에서 가장 많은 문제가 발생하지만, 누구도 의사결정을 주도하지 못하는 경우가 다수 발생한다. 평가항목을 구체화하는 과정에서 개발기관과 사용자의 견해 차이가 생길 수 있고 평가결과에 대해서도 여러 가지 이견이 발생한다. 평가결과가 요망수준을 충족하면 문제가 없으나 평가결과 요망수준을 충족시키지 못하면 연구개발사업을 어떻게 종결할지 의사결정을 하여야 한 다. 시험평가에서 부적합 판정 시는 다음과 같은 절차로 규정26)되어있다. "방사청은 운용시험평가 결과가 전투용 부적합으로 판정된 경우 위원회 또는 분과위원회에 사업의 중단 또는 계속 추진 여 부를 보고하되, 필요 시 심의 - 조정을 할 수 있다. 일부 시험평가 항목을 미충족하였으나, 군 필요성 에 의해 획득이 추천되는 경우 관련 선행조치 후 재판정하거나 부분 재시험평가를 수행할 수 있다.'

요구했던 성능에 부족한 장비라도 필요한 경우 획득추천을 요청할 수 있고, 획득이 추천된 경우 일단 성능이 부족한 장비를 사용하면서 성능개량을 요구할 수도 있다. 이렇게 되면 성능에 미달하 여 연구개발에 실패한 장비를 사용하도록 '부실하게 평가했다'라는 지적과 '개발업체 봐주기' 의혹 을 받을 수 있어 군은 사업실패로 종결하고 새롭게 소요를 결정하여 새로운 사업으로 다시 시작하 는 방법을 택하고 있다. 그런 이유로 지금까지 있었던 여러 연구개발 사업 중 ‘획득추천’ 사례는 찾 기 어렵다. 전술교량의 사례와 같이 목표했던 성능에 도달하지 못했더라도 불요불급한 장비였다면 연구개발하여 완성된 장비를 ‘연구개발 실패’로 사업을 종결하고 그보다 낮은 성능으로 다시 소요 를 결정하는 절차를 밟을지 의심스럽다.

시험평가 이후 일부 성능이 미달한 경우 사업의 중단 또는 계속 추진 여부를 두고 의사결정이

25) R.O.K. Ministry of National Defense. Defense Force Development Instruction Article 31 (Composition and Operation of the Integrated Concept Team)

26) R.O.K. Ministry of National Defense. Defense Force Development Instruction Article 83-6 (Performing Operation Test \& Evaluation) 
지연되는 경우가 다수 발생하며 사업을 계속 추진하는 경우에도 전 항목 재시험, 부분 재시험을 결 정하기 위해 많은 시간을 보내는 사례가 다수 발생하게 된다. $30 \mathrm{~mm}$ 대공포 비호 사업도 생산 당시 장갑 두께와 속력 등이 군 요구 성능(ROC)에 미치지 못했다는 이유로 중단되어 23년이 지나서 전 력화할 수 있었고 TICN 사업도 무전기 성능이 요구성능을 충족하지 못하여 수년간 사업이 지연되 었고 K-2 전차 파워팩도 성능미달로 사용하지 못하면서 시간과 비용을 낭비하였다. 여기서 생기는 가장 심각한 문제는 적기에 전력화되지 못해서 발생하는 안보 공백인데 이 문제는 언급조차 되지 않는 이상한 현상이 반복되고 있다.

\section{IV. 결론 및 논의}

본 연구는 우리 군의 군사력 건설 시스템의 문제를 (1) 소요결정과정의 문제, (2) 절차의 복잡성과 경직성, (3) 의사결정 회피 및 지연)의 3 가지 측면에서 살펴보았다. 분석결과, 군사력 건설 시스템은 견제와 균형, 비리 예방을 위한 투명성 제고에 중점을 두고 있어 합동성과 효율성을 제고하고 의사 결정 시간을 단축하기 위해 개선이 요구된다. 즉, 군사력 건설 시스템의 조직과 임무수행체계를 정 비하고 그에 맞게 법규를 정비해야 한다.

우선 군사력 건설의 시초가 되는 소요결정 과정의 문제는 합동전투발전체계를 제대로 적용하고 합동성 차원에서 합참이 주도하고 각 군 본부가 지원하는 관계로 임무와 기능을 조정하고 조직을 정비하여야 한다. 합동작전개념에 근거하여 합동작전요구능력서와 소요제기지침서에 제시된 범위 내에서 소요를 제기하도록 하고 범위를 초과하는 소요제기는 한국국방연구원에서 수행하고 있는 소요검증과 동시에 합참(전투발전부)에서 합동성에 기초하여 필요성을 재검증하는 절차를 거치도 록 하여야 한다. 특히, 소요결정 절차를 수정하고 정상화하기 위해서 합참의 전투발전부를 대폭 증 편하고 전투발전 조직에 대한 업무 통제체계를 조정하여야 한다. 군정과 군령이 분리된 상태에서 합참은 각 군의 전투부대에 대하여 작전지휘가 가능하지만, 비전투부대인 각 군의 교육사나 각 군 전투발전조직을 통제할 권한이 없다. 그러다 보니 각 군 차원의 교리발전이나 전력소요에 대한 전 투실험 등은 활발히 이루어지고 있으나 오히려 합동차원에서는 조직이 열악하고 시행은 어려운 현 실이다. 합동전투발전체계에서 제시하는 전투실험은 실제로 수행할 수 없는 문서상의 절차에 불과 하다. 용병과 양병 또는 군정과 군령으로 구분하여 상부지휘구조를 분리하면서 발생한 현상으로 군 사력 건설은 용병과 양병이 연계된 기능이며 군정과 군령의 공통부분으로 불가분의 관계라고 볼 수도 있다.

또한, 국방부 전력자원관리실을 중심으로 현재 제도의 문제점을 보완하기 위한 제도개선 연구가 진행되고 있다. 하지만, 법규 측면에서 소요결정부터 사업착수까지도 5년 이상이 소요되는 현행 획 득시스템의 경직성으로 인해 시시각각 바뀌는 기술변화에 대응하는 데 한계점이 존재한다. 그러므 
로 사업관리 절차상 분절되고 경직된 부분을 해소하고 유연하고 효율적인 사업관리가 가능하도록 규정을 정비하여야 한다. 앞에서 제시한 바처럼 각각의 단계에서 책임기관들은 앞 단계에서 산출된 결과를 받고 나서 해당 기관에 부여된 단계를 진행하고 있다. 이로 인해 사업추진 중에 문제가 발 생하면 다시 소요단계로 돌아가 처음부터 순서대로 진행하는 경직된 업무수행방식이 지속되고 있 다. 이를 근본적으로 해소하기 위해 사업 관련 이해관계자가 전체 사업기간을 단축하고 효과적으로 업무를 수행할 수 있도록 자율 보장과 책임 준수에 관한 법규 정비가 선행될 필요가 있다.

지금까지 살펴본 것처럼 한국군의 군사력 건설 시스템은 표면적으로는 합리적이고 체계적인 구 조를 갖추었으나 긴박한 안보환경 변화와 빠르게 발전하는 과학기술을 군사력 건설에 반영하기 위 해서는 개선할 점이 다수 존재한다. 가장 중요한 문제는 합참이 합동작전개념에 기초하여 군사력 건설을 주도할 필요가 있다. 평시 현행작전은 천안함 폭침이나 연평도 포격전과 같이 합동전력을 투사할 필요성이 있는 상황을 제외하면 대부분 작전사 이하에서 조치되는 상황이다. 따라서 향후 합참은 중장기 군사력 건설, 군사전략 등 최고 군사기구로서 중심적 역할에 중점을 둘 필요가 있으 며, 안보 - 전략환경의 변화에 따라 장기적인 대응전략을 수립하고 대응능력을 건설하는 핵심적인 기능을 강화할 수 있도록 조직과 임무수행체계, 법규 등에 대한 변화가 요구된다.

\section{Acknowledgements}

We would like to thank Editage (www.editage.co.kr) for English language editing.

\section{Declaration of Conflicting Interests}

The author(s) declared no potential conflicts of interest with respect to the research, authorship, and/or publication of this article. 


\section{Reference}

Bae. S., Ku, X., Park. C., \& Kim. J. (2020). A Latent Topic Modeling approach for Subject Summarization of Research on the Military Art and Science in South Korea. Korean Journal of Military Art and Science, 76(2), 181-216. https://doi.org/10.31066/kjmas. 2020.76.2.008

Lee. G. (2018). Development Direction of Defense Decision System for Effective Armed Forces Construction: The Role of the Ministry of Defence and the Measures to Strengthen the Effectiveness of Mid-term Defense Program. The Quarterly Journal of Defense Policy Studies, 34(1), 7-36. https://doi.org/10.22883/jdps.2018.34.1.001

Lee, J. (2020). A literature review of recent topics in Korean Military Art and Science. Journal of Advances in Military Studies, 3(3), 187-211. https://doi.org/10.37944/jams.v3i3.87

Seo, S., Jang, S., Kim, Y. (2017). Innovative Method of Korean Military Force Building System in The 4th Industrial Revolution Period. Defense Policy Study, 33(1), 171-201. https://doi.org/10.22883/jdps.2017.33.1.006

Seo, S. \& Kim, Y. (2017). European Armed Forces Development System, Combat development System, Defense Planning Management System and Defense Acquisition System. Strategic Studies, 24(3), 111-150. https://www.kci.go.kr/kciportal/ci/sereArticleSearch/ciSereArtiView. kci?sereArticleSearchBean.artiId=ART002287234

Kim, Y. (2018). Innovation of Acquisition System by Ensuring the Application of Evolutionary ROC. Defense Technology, 467, 32-37. http://www.dbpia.co.kr/journal/articleDetail?nodeId= NODE07293465

Defense Acquisition Program Administration. Defense Acquisition Act. https://www.law.go. kr/\%EB\%B2\%95\%EB\%A0\%B9/\%EB\%B0\%A9\%ЕC\%9C\%84\%ЕC\%82\%AC\%ЕC\%97\%85 $\% \mathrm{~EB} \% \mathrm{~B} 2 \% 95$

Defense Acquisition Program Administration. Enforcement Decree of the Defense Acquisition Program Act. https://www.law.go.kr/\%EB\%B2\%95\%EB\%A0\%B9/\%EB\%B0\%A9\%EC\% 9C\%84\%EC\%82\%AC\%EC\%97\%85\%EB\%B2\%95\%EC\%8B\%9C\%ED\%96\%89\%EB\%A0\%B9

Defense Acquisition Program Administration. Enforcement Regulation of the Defense Acquisition Program Act. https://www.law.go.kr/\%EB\%B2\%95\%EB\%A0\%B9/\%EB\%B0\%A9\%EC\% 
9C\%84\%EC\%82\%AC\%EC\%97\%85\%EB\%B2\%95\%EC\%8B\%9C\%ED\%96\%89\%EA\%B7\%9 $\mathrm{C} \% \mathrm{EC} \% \mathrm{~B} 9 \% 99$

Defense Technology Quality Institute (2013). Dictionary of Terms and Conditions for Defense Science and Technology. https://dtims.dtaq.re.kr/vps/OINF_viewDictionaryOfDST.do

R.O.K. Ministry of National Defense. Directive on the Defense Planning and Management Framework. https://www.law.go.kr/admRulLsInfoP.do?admRulId=26461\&efYd=\&admRulNm= $\% \mathrm{EA} \% \mathrm{~B} 5 \% \mathrm{AD} \% \mathrm{~EB} \% \mathrm{~B} 0 \%$ A9\%ЕA\%B8\%B0\%ED\%9A\%8D\%EA\%B4\%80\%ЕB\%A6\%AC \%ЕА\%В8\%B0\%ЕB\%В3\%B8\%ED\%9B\%88\%ЕB\%А0\%В9

R.O.K. Ministry of National Defense. Directive on the Defense Force Development. https://www. law.go.kr/\%ED\%96\%89\%EC\%A0\%95\%EA\%B7\%9C\%EC\%B9\%99/\%EA\%B5\%AD\%EB\% B0\%А9\%ЕC\%А0\%84\%ЕB\%A0\%А5\%ЕB\%В0\%9C\%ЕC\%A0\%84\%ЕC\%97\%85\%ЕB\%AC $\% \mathrm{~B} 4 \% \mathrm{ED} \% 9 \mathrm{~B} \% 88 \% \mathrm{~EB} \% \mathrm{A0} \% \mathrm{~B} 9$

R.O.K. Joint Chiefs of Staff (2020). Joint Manual 10-2 Military Terminology Dictionary for Joint\& Combined Operation. http://dl.nanet.go.kr/law/SearchDetailView.do?cn=MONO1200504230 R.O.K. Joint Chiefs of Staff. Joint Combat Development Instruction. 
국문초록

https://doi.org/10.37944/jams.v4i2.104

\title{
한국군 군사력 건설 시스템의 문제점 진단
}

\author{
강천수* - 김주찬**
}

우리 군은 1970년대에 자주국방의 기치를 내세우고 시작된 율곡사업을 추진하면서부터 군사력 건설 시스 템에 관한 관심을 갖고 발전을 추진하여 왔다. 현재 우리 군의 군사력 건설 시스템은 합동전투발전체계에서 소요를 결정하고 소요가 결정되면 국방기획관리체계에서 예산을 반영하고 국방획득체계에서 획득사업을 관 리하는 표면적으로는 아주 체계적이고 합리적인 제도로 보인다. 그러나 실제 현장의 상황을 세부적으로 보면 많은 문제점을 가지고 있다. 군사력 건설의 소요결정과정에서 각 군 간의 경쟁이 치열하고 검증이 제한되는 문제, 소요에 대한 기준과 근거가 모호하거나 절차와 규정이 복잡하고 경직되어 있는 문제, 안보환경의 변화 나 빠르게 발전하는 과학기술을 군사력 건설에 반영하지 못하는 문제 등을 대표적으로 들 수 있다. 이 중에서 많은 문제가 합동참모본부가 합동작전개념에 기초하여 군사력 건설을 주도해야 하지만, 현재는 현행작전에만 몰입하여 중장기 군사력 건설, 군사전략 등 최고 군사기구로서 중심적 역할은 소홀하게 수행하여 발생하는 문 제이다. 이에 따라, 합참이 안보 - 전략환경의 변화에 따라 장기적인 대응전략을 수립하고 대응능력을 건설하 는 국방조직의 핵심적인 기능을 제대로 수행하도록 조직과 임무수행체계, 법규를 개정할 필요성을 제기한다.

주제어 : 군사력 개발, 합동 전투 발전체계, 방위계획 및 운용체계, 국방 획득 제도

* (제1저자) 광운대학교 방위사업학과, 박사수료, 국방개혁위원회 자문위원, choekang@korea.com ** (교신저자) 광운대학교 행정학과, 교수, jckim@kw.ac.kr 